\title{
Review Article \\ Deposition Methods for Microstructured and Nanostructured Coatings on Metallic Bone Implants: A Review
}

\author{
Bailey Moore, Ebrahim Asadi, and Gladius Lewis \\ Department of Mechanical Engineering, The University of Memphis, Memphis, TN 38152, USA \\ Correspondence should be addressed to Ebrahim Asadi; easadi8@yahoo.com
}

Received 10 October 2016; Revised 11 December 2016; Accepted 21 December 2016; Published 9 January 2017

Academic Editor: Hongchao Kou

Copyright (C) 2017 Bailey Moore et al. This is an open access article distributed under the Creative Commons Attribution License, which permits unrestricted use, distribution, and reproduction in any medium, provided the original work is properly cited.

\begin{abstract}
A review of current deposition processes is presented as they relate to osseointegration of metallic bone implants. The objective is to present a comprehensive review of different deposition processes used to apply microstructured and nanostructured osteoconductive coatings on metallic bone implants. Implant surface topography required for optimal osseointegration is presented. Five of the most widely used osteoconductive coating deposition processes are reviewed in terms of their microstructure and nanostructure, usable thickness, and cost, all of which are summarized in tables and charts. Plasma spray techniques offer cost-effective coatings but exhibit deficiencies with regard to osseointegration such as high-density, amorphous coatings. Electrodeposition and aerosol deposition techniques facilitate the development of a controlled-microstructure coating at a similar cost. Nanoscale physical vapor deposition and chemical vapor deposition offer an alternative approach by allowing the coating of a highly structured surface without significantly affecting the microstructure. Various biomedical studies on each deposition process are reviewed along with applicable results. Suggested directions for future research include further optimization of the processmicrostructure relation, crystalline plasma spray coatings, and the deposition of discrete coatings by additive manufacturing.
\end{abstract}

\section{Introduction}

Complications, such as necrosis, resulting from the exothermic reaction of the cement, have led to much research in uncemented bone implants, especially in young, active patients [1-4]. Abdulkarim et al. [5] published a metaanalysis of cemented versus uncemented joint implants that showed that patients favor uncemented implants. An uncemented bone implant relies on osseointegration, the condition where the implant and the surrounding bone are in direct contact, allowing load bearing with no progressive relative motion [6]. Poor osseointegration is currently the cause of extended patient recovery time and premature failure in uncemented bone implants $[7,8]$. Furthermore, longevity of an uncemented bone implant relies on osteoconduction, which is the ability of bone growth into the implant surface. Metal alloys such as titanium and its alloys are widely used for the manufacture of bone implants as they are biocompatible, and they exhibit good corrosion resistance, excellent fatigue strength, low density, and excellent formability and machinability $[9,10]$. Titanium and most other metals, however, exhibit low wear resistance and low osteoconduction in as-machined form. Applying an appropriate organic or inorganic coating to such bone implants can enhance the substrates osteoconduction, corrosion resistance, biocompatibility, surface hardness/wear resistance, and fatigue properties.

There are many reviews that cover optimal implant surface characteristics for osseointegration and biocompatibility $[7,8,11-16]$. Also, various methods of coating deposition such as thermal spray [17-19], electrodeposition [19-21], and ion-beam processing [22-24] on the implant surface have been reviewed. The deposition of specifically biocompatible coatings has also been extensively researched and reviewed [25-30]. In spite of this, there is no source in literature that cross-analyzes many deposition methods used on bone implants in view of the capability of producing the necessary microstructure and nanostructure of bone implant surfaces. Thus, the objective of this paper is to review the most widely used microstructured and nanostructured deposition methods and coatings on metallic bone-implant applications. 
First, desired implant surface properties that enhance osseointegration are presented. Various deposition methods are reviewed with the goal being to summarize advantages and disadvantages of each process in relation to microstructured and nanostructured biomedical coating. Finally, a brief list of suggestions for future research is given.

\section{Desirable Coating Properties to Promote Osseointegration}

Osteoconductive coatings such as hydroxyapatite (HA) and other calcium phosphates are widely used as they exhibit both high mechanical properties and biocompatibility. However, studies indicate that the surface topography is as important, if not more so, as the implant surface material for optimal osseointegration [31-35]. Taniguchi et al. [14] studied the effect of pore size on titanium implants and concluded that when all other characteristics were controlled and simply pore size was varied, specimens with pore size of $600 \mu \mathrm{m}$ performed significantly better than specimens with pore size of $300 \mu \mathrm{m}$ and $900 \mu \mathrm{m}$. In addition to the microstructure, the nanostructure of the surface should be considered. In a study by Khang et al. [36], when coating grain size decreased from 167 to $24 \mathrm{~nm}$ osteoblast adhesion increased by $51 \%$ and fibroblast adhesion by $235 \%$.

Thus, it is concluded that in order for a surface to exhibit bone-bonding properties it should have microtopography with submicron or nanometer undercuts and pores. The coating process to be selected should exhibit the ability to control and vary pore size from several hundred nanometers to several hundred micrometers, pore structure, and nanostructure of the coating.

\section{Coating Deposition Processes}

The following section focuses on five processes as these techniques are widely used to produce bone-implant coatings: electrodeposition, physical vapor deposition/chemical vapor deposition, thermal spray, and aerosol deposition. The advantages and disadvantages are summarized in view of the aforementioned surface requirements.

3.1. Thermal Spray. This deposition method is advantageous in that the temperature range achieved (the plasma core temperatures are between 8000 and $14000 \mathrm{~K}$, while the plume can be down to about $2000 \mathrm{~K}$ at conventional spray distances) allows the coating of an extremely wide variety of materials with rapid deposition rate [37-40]. Thermal spray processes to be reviewed are categorized as cold spray, combustion spray, electric arc spray, and plasma spray. Combustion spray methods discussed are high-velocity oxy-fuel spray and detonation gun spraying. Likewise, pertinent plasma spray processes are direct current blown arc spray, radio frequency inductively coupled spray, and plasma transferred wire arc spray.

3.1.1. Cold Spray. Cold spray involves the release of a high pressure gas through a convergent-divergent Laval nozzle, creating a supersonic stream which is used to accelerate coating powder at the workpiece [41]. As the particles are not molten or semimolten, cold spray adhesion can be relatively high. High kinetic energy results in cleaning (removal of oxidation) and activation of the substrate. Each subsequent layer of coating sprayed further bonds the previous layer allowing excellent metallurgical bonding of the coating and substrate. Cold spray is mainly used for metals or alloys, with HA being an exception. HA was deposited using cold spray in a study by Hasniyati et al. [42]. Pure magnesium substrates were heated to $350-550 \mathrm{~K}$ and ground to varying surface roughness between 240 grit and 2000 grit. Nozzle standoff distance and number of sprays were varied from 20 to $60 \mathrm{~mm}$ and from 5 to 10 , respectively. The responses to be maximized were thickness, nanohardness, and elastic modulus. A response optimizer indicated HA of thickness $46.3 \mu \mathrm{m}$, 436.5 MPa nanohardness, and 43.9 GPa elastic modulus was produced with $22.7 \mathrm{~mm}$ standoff distance, 649.2-grit surface roughness, and $769 \mathrm{~K}$ substrate temperature. Further research is necessary to relate these factors to osseointegration.

3.1.2. High-Velocity Oxy-Fuel Spray. High-velocity oxy-fuel spraying (HVOF) and detonation gun (D-Gun) are two combustion spray techniques that have been used to coat bone implants. HVOF [43] is a spray process in which combustion is achieved in a pressurized chamber once oxygen and a fuel gas (i.e., methane) are injected, resulting in temperatures of up to $3,700 \mathrm{~K}$ that then exit at speeds up to $2,000 \mathrm{~m} / \mathrm{s}$ through a de Laval-type nozzle. This coupling of highly plasticized particles impacting at supersonic velocities results in a highdensity coating. Gas temperature and velocity are the key parameters to control the efficiency of HVOF coating process [44]. A study by Khor et al. [45] investigated the precipitation of an apatite layer on an HVOF deposited HA coating in vitro. The results demonstrated increased precipitation in areas of $\mathrm{Ca}^{2+}$ concentration as a result of dissolution of secondary phases such as tricalcium phosphate, tetracalcium phosphate, or amorphous calcium. Thus, an increased composition of dissolvable secondary phases on the surface of calcium phosphate coatings could lead to expeditious precipitation of an apatite layer.

3.1.3. Detonation Gun Spray. Detonation gun spraying [46] has also been used to deposit coating on bone implants. This method involves the detonation, at a frequency of 3$100 \mathrm{~Hz}$, of a fuel gas and oxygen introduced into a chamber with powder coating material. Most coating aspects including density, corrosion barrier, hardness, wear resistance, and bond strength are improved, resulting in a smooth coating with minimal oxidation. $\mathrm{Al}_{2} \mathrm{O}_{3}-13 \mathrm{TiO}_{2}$ was deposited on biomedical grade $\mathrm{Ti}-13 \mathrm{Nb}-13 \mathrm{Zr}$ by detonation gun spray to increase corrosion and wear resistance [47]. The presence of $\mathrm{TiO}_{2}$ and similar oxides is reported to contribute to the formation of apatite and bone-like tissue on the surface of implant [48]. The coating also exhibited $43 \%$ and $33 \%$ increase, respectively, in corrosion and wear resistance as a result of the presence of larger volume fraction of nanosized particles and lower porosity, when compared to uncoated titanium alloy. 
TABLE 1: A summary of a selection of characteristics of thermal spray processes* .

\begin{tabular}{|c|c|c|c|c|c|c|}
\hline \multirow{2}{*}{ Characteristic } & \multirow{2}{*}{ Cold spray } & \multicolumn{2}{|c|}{ Combustion } & \multicolumn{3}{|c|}{ Plasma } \\
\hline & & HVOF & D-Gun & Nontransferred arc & RF inductive & Transferred arc \\
\hline Gas temperature $(\mathrm{K})$ & $>300$ & $3000-3300$ & $\geq 4000$ & $12,000-14,000$ & $8,000-10,000$ & $12,000-14,000$ \\
\hline Substrate temperature $(\mathrm{K})$ & $>300$ & $350-450$ & $350-450$ & $350-400^{* * *}$ & $350-400^{* * *}$ & Fuses base metal \\
\hline Particle velocity $(\mathrm{m} / \mathrm{s})$ & $\leq 900^{* *}$ & $\leq 700$ & $\leq 3000$ & $\leq 560$ & $15-20$ & 490 \\
\hline Bond strength (MPa) & $\leq 50$ & $>80$ & $>70$ & $14-69$ & $\leq 35$ & $>200$ \\
\hline Coating thickness (mm) & $0.01-0.05$ & $0.05-5.0$ & $0.05-5.0$ & $0.05-5.0$ & $0.05-5.0$ & $0.5-6.0$ \\
\hline Porosity (\%) & $1-5$ & $<2$ & $<2$ & $1-5$ & $1-5$ & $<2$ \\
\hline
\end{tabular}

* Data on characteristics taken from references [39-41].

${ }^{*}$ Particle velocity must be above the critical velocity for specified coating material.

${ }^{* * *}$ Without the use of additional cooling system.

3.1.4. Direct Current Blown Arc Spray. Direct current blown arc spraying [49] consists of a nontransferred arc (contained in the nozzle) as the heat source to generate plasma which melts the coating material and accelerates it toward the workpiece. The high degree of particle melting and the high velocity obtained result in higher coating density and bond strength than the aforementioned thermal spray processes.

3.1.5. Radio Frequency Inductively Coupled Spray. Radio frequency inductively coupled plasma spraying utilizes an inductively coupled radio frequency plasma torch for the generation of the hot energetic gas stream. This method allows for the elongation of the plasma plume, making it advantageous for materials requiring a longer dwell time to develop a fully liquid state $[18,39]$.

3.1.6. Plasma Transferred Wire Arc Spray. Plasma transferred wire arc spray process $[50,51]$ is similar to direct current blown arc spraying with the exception that the coating material feedstock is fed outside the nozzle and made the anode, transferring the arc further outside the nozzle. The metal is sprayed at supersonic velocities, increasing the density and bond. Similarly, plasma spray welding [52] is a process whereby the arc is transferred to the substrate (the anode). Once on the substrate, the coating and the surface of the substrate are melted by the plasma, thereby fusing them together. Variation in torch power levels allows for either a coating that is only fused to the substrate or a coating that is mixed within the substrate. Key process parameters for plasma spray are plasma temperature, particle velocity, consistency of the powder/wire feeder, and spray environment. The powder/wire feeder construction must ensure uniform, reproductive inputs in order to precisely control the coating characteristics [53]. While plasma spray can be applied in a large variety of environments, the environment can affect the coating properties and must be considered.

3.1.7. Plasma Spray of Hydroxyapatite. Plasma spray is one of the most widely used deposition methods for calcium phosphate on metallic bone implants due to its rapid deposition rate and low cost [54]. Improving the mechanical stability of plasma-sprayed calcium phosphate coatings has been a subject of research. Yang et al. [55] studied the correlation between residual stress and mechanical stability in plasma-sprayed HA. Coating thicknesses of $50 \mu \mathrm{m}$ and $200 \mu \mathrm{m}$ were deposited and all other parameters were fixed. The thinner coating exhibited lower residual stress as a result of reduced melting of the $\mathrm{HA}$ and superior mechanical stability in vivo. Yang et al. [27] presented the addition of carbon nanotubes in order to improve the crystallinity, strength, and toughness of HA. For this study, HA powder, particle size $10-50 \mu \mathrm{m}$, was mixed with carbon nanotubes, outer diameter $40-70 \mathrm{~nm}$, length $0.5-2 \mu \mathrm{m}$, for 18 hours to produce powder feedstock that was injected with argon in the plasma spray gun. The spray parameters were optimized to result in a uniformly thick $(\sim 110 \mu \mathrm{m})$, homogeneous HA coating with $4 \mathrm{wt} \%$ carbon nanotubes. A higher degree of crystallinity, which increases osteoconduction and reduces biodegradation [56], was observed in the HA coating with carbon nanotubes when compared to those without carbon nanotubes. The carbon nanotubes provide enhanced strength thereby increasing the fracture toughness of the HA by up to $56 \%$.

While thermal spray offers a rapid deposition rate at low cost, application of controlled-nanostructured coatings is still a difficulty as high-density coatings with less than $10 \%$ porosity are a typical result of thermal spray. Additionally, some sources suggest that the uses of plasma-sprayed calcium phosphate coatings as the main bone-implant interface are at a risk of loosening as the high concentration of secondary phases increases dissolution of the coating [57]. Likewise, deposition of calcium phosphate coatings can result in low adhesion to the substrate further reducing the life of the implant. For this reason, further research into the use of alternative methods for depositing osteoconductive coatings is necessary. A summary of key process characteristics of thermal spray can be read in Table 1 .

3.2. Electrodeposition. An alternative to depositing osteoconductive coatings is electrodeposition. Electrodeposition [58] is an electrolytic coating process whereby metal ions, suspended in a solution, are deposited onto a cathodic workpiece when a direct current is passed through the solution. This process is, by and large, one of the most inexpensive engineering coatings. Gurrappa and Binder [21] successfully coated titanium with Type 1 mineralized collagen sponge using an electrodeposition process known as electrochemical deposition [21]. Voltage potential was varied demonstrating 
the ability to control the morphology of the coating. At lower potential of $1.7 \mathrm{~V}$, a dense coating with low degree of mineralization resulted. Increasing the voltage to $2.5 \mathrm{~V}$ produced a coating of high porosity and high degree of mineralization. Potential greater than $2.5 \mathrm{~V}$ resulted in the mineralization of collagen in the bath, while not coating the substrate. The microstructure of this coating was characterized by distinct scaffolding of mineralized collagen underneath which was nanoporous calcium phosphate layer. HA-chitosan coatings produced by electrophoretic deposition demonstrated that the coating porosity is also dependent on the bath concentration [59]. Suspensions with HA concentration above $0.7 \mathrm{~g} / \mathrm{l}$ resulted in a porous microstructure. Coating thickness was $100 \mu \mathrm{m}$ with a lattice of loosely packed, needle-shaped HA particles with mean size of $200 \mathrm{~nm}$ resulting in nanometer pores and undercuts. Recent research displayed the ability to produce nanocrystalline (grain size $<10 \mathrm{~nm}$ ) coatings and materials. Nanocrystalline coatings have been observed to be five times harder, with a $50 \%$ reduction in coefficient of friction, and three to ten times stronger than conventional coatings (grain size $>10 \mu \mathrm{m}$ ) [22].

The ability to control the coating microstructure and nanostructure, as well as morphology and mineralization by varying parameters such as deposition potential/current, bath composition, temperature, and deposition time, made electrodeposition a novel method for producing osteoconductive coatings. There are some notable disadvantages related to electrodeposition. Process parameters must be optimized for each workpiece to obtain uniform thickness [60]. Environmental concerns also arise from the process such as the acidic, alkaline, and cyanide discharge.

\subsection{Physical Vapor Deposition/Chemical Vapor Deposition.} Physical vapor deposition is the process of forming on a substrate a thin, hard film consisting of submicron particles resulting from evaporation by plasma, arc discharge or the like $[61,62]$, or mechanical removal from a target. In order to facilitate the process of evaporation, PVD typically takes place in a vacuum chamber. Thermal evaporation and sputtering are two types of PVD used for biomedical coatings.

\subsubsection{Thermal Evaporation PVD. Thermal evaporation PVD} involves heating the coating metal to the point of evaporation by means of a resistance heat source, high-energy arc or electron beam. In the case of a coating metal with relatively low melting point, a resistance source can be used to heat a crucible containing a powdered form of the coating. This method does not allow the evaporation of metals with high melting temperatures, such as molybdenum and tungsten. Evaporation of refractory metals can be achieved by heating with an intense beam of electrons. One or multiple 10kilovolt, 1 Amp beams are directed into the crucible, which is water-cooled, evaporating the material [63]. Cathodic arc evaporation (CAE) PVD [64] utilizes a high-energy arc that heats the target and generates $50-100 \%$ ionized metal vapor. This ionized vapor accelerates toward the substrate kept at a negative bias of $500-2000 \mathrm{~V}$ at speeds up to $1-2 \times 10^{4} \mathrm{~m} / \mathrm{s}$ [64]. This creates a highly dense coating with better adhesion. Target composition, substrate temperature, bias voltage, gas flow, and ion-bombardment rates are the key parameters in the CAE process [65]. Onder et al. [66] used CAE to apply magnesium doped TiN onto the surface of titanium substrates. The result was the formation of magnesium substituted HA nodules on the scale of $2-5 \mathrm{~nm}$ when placed into simulated body fluids. This offers the potential to produce implants that induce on-site nanostructured HA production, thereby facilitating osseointegration.

3.3.2. Sputter PVD. As opposed to heating the coating metal, magnetron sputter PVD is a process by which ions are mechanically ejected by ion-bombardment from the coating metal and propelled into the substrate [67]. Important parameters in magnetron sputtering are magnetron power, ion current density, substrate bias, gas pressure, target composition, and substrate temperature [68]. Cheang and Khor [28] present a sputtering process used for coating HA. Assputtered coatings were observed to be dense, comprised of $100-200 \mathrm{~nm}$ particles. Post heat treatment increased the crystallinity up to $68 \%$ and reduced residual stress. Scanning electron micrograph showed an apatite-like microstructure. In vitro, the HA coating dissolved creating localized calcium and phosphate concentrated environments followed by the formation of a bone-like mineral layer. Significantly higher mineralized extracellular matrix was formed on coated surfaces in comparison to as-machined titanium surfaces. In vivo, it was found that the ultimate interfacial strength was not significantly lower than that of other common deposition processes.

3.3.3. Ion-Beam Assisted Deposition. Ion-beam assisted deposition (IBAD) is a process that combines physical vapor deposition and ion-beam bombardment in a vacuum. The main advantage of IBAD is the ability to produce biocoatings with significantly higher adhesive strength compared to traditional coating processes. This is due to a zone between the coating and substrate in which the atoms of the coating and substrate are intermixed. Cui et al. [69] used IBAD to coat titanium substrate with HA. The result was crystalline HA with increased adhesion and reduced interfacial deficiencies exhibited by plasma-sprayed HA.

3.3.4. Chemical Vapor Deposition. As opposed to most PVD techniques, chemical vapor deposition (CVD) is desirable for the deposition of a coating on complex geometric workpieces uniformity. At a rudimentary level, CVD utilizes chemical reactions of a precursor gas in a heated chamber containing the workpiece [70]. The products of this chemical reaction are deposited in thin layers on the surface of the substrate and the byproducts are exhausted from the system. CVD has been used to deposit $\mathrm{TiO}_{2}$ on Ti machined implants [71]. Osseointegration of these coated implants was compared to uncoated Ti machined implants in vivo. The affinity index of implants coated with $\mathrm{TiO}_{2}$ proved to be significantly higher than that of uncoated Ti implants in both cortical and cancellous bone at only 12 weeks. While this process does offer significant advantages, the near-volatility of precursor gases at room temperature and the temperature at which the process takes place, up to $1600^{\circ} \mathrm{C}$, are notable disadvantages. 
PVD/CVD processes require highly controlled equipment and vacuum chambers, greatly increasing cost. Not only does initial capital investment increase, facilities required for the high temperature CVD process, as well as the expenses to handle the volatile gases, also increase the cost. The production of dense nanoscale PVD coatings offers the ability to deposit osteoconductive, biocompatible coatings on nanopore surfaces without altering the microstructure. That is, the surface of an implant can be modified by techniques such as acid etching or the addition of nanotubes of the native material thereby creating a strong microstructural interface for bone ingrowth. Coating of osteoconductive materials can then be deposited without significant topographical change to the surface. Nanotubes of Ti-30Nb- $x \mathrm{Zr}$ and Ti-35Ta- $x \mathrm{Hf}$ alloys have been vacuum arc welded to the surface of titanium alloy implants, creating a nanopore surface $[72,73]$. While these alloys are biocompatible, it is recognized that the addition of a bioactive coating is advantageous for chemical bonding with bone tissue; thus HA is then deposited using electron beam physical vapor deposition. The dissolution of HA encourages bone ingrowth into the titanium alloy nanoscale scaffolding resulting in expedited osseointegration and strong bond strength.

3.4. Aerosol Deposition. Aerosol deposition, also known as vacuum cold spray [74] or vacuum kinetic spraying [75], is analogous to cold spraying. As opposed to high pressure gas accelerating the coating particles, toward a substrate at atmospheric pressure, aerosol deposition consists of placing substrate in a vacuum chamber which draws the gas/atomized particle solution through a de Laval nozzle directed at the substrate at velocities of $100-600 \mathrm{~m} / \mathrm{s}$ [76]. Aerosol deposition uses smaller particle sizes than cold spray, allowing for lower speeds and temperatures. Bonding occurs as a result of reduction of crystallite sizes by fracture and/or plastic deformation. There are three major approaches to manufacturing porous, nanostructured coatings using aerosol deposition. The first approach is the use of a colloidal dispersion of organic and/or inorganic submicronic particles or nanoparticles. The porosity is a result of the interstitial volume between the close packed particles. Also, secondary heat treated processes can be used to remove the organic particles, a sacrificial template, in which a porous coating is obtained. Therefore, the interstitial space between particles and the voids left by the organic material. A second procedure consists of a reactive sol-gel system combined with molecular surfactants or amphiphilic block copolymers. With this procedure, evaporation-induced self-assembly (EISM) or evaporation-induced micelle packing (EIMP) generates mesoporous microspheres. This process can be tuned to produce aerosol particles of $100 \mathrm{~nm}-20 \mu \mathrm{m}$. Yet another process utilizes the combination of the first two. With this process, the microstructure and nanostructure can be finely tuned by both the size of the sacrificial organic particles used and the EISM/EIMP generated microspheres [77]. Important parameters that influence the final morphology of the coating are the sol-gel chemistry, the ageing time of the solution, and the particle sizes used.
Hahn et al. [78, 79] developed an aerosol process using soluble $\beta$-tricalcium phosphate mixed with HA to form a coating on titanium bone implants. A ratio of $30 \%$ HA and $70 \% \beta$-tricalcium phosphate was reported to exhibit the highest cellular response. This coating was comprised of a complex nanostructured architecture with most voids on the order of $100 \mathrm{~nm}$. Other mixtures tested were silicondoped and fluorine-doped HA. A matrix of irregular shaped particles sized $0.5-2 \mu \mathrm{m}$ was observed in both regardless of composition. Kubo et al. [80] produced highly uniform porous thin films using an aerosol deposition method. Pore sizes of 60,100 , and $150 \mathrm{~nm}$ were produced by deposition nonagglomerated nanoparticles of 7.9, 17.6, and $36.2 \mathrm{~nm}$ geometric mean diameter, respectively. Coating composition was indicated to have little to no effect on the controllability of porosity. Thus, it is concluded that aerosol deposition is a viable means to create controlled nanostructured and microstructured coatings of various composition. One notable disadvantage is a very low deposition efficiency, often less than $1 \%$ [76]. In order to improve this process, further investigation into increasing the process efficiency is necessary.

\section{Comparison of Coating Deposition Processes}

A summary of the typical coating thickness of the reviewed processes is shown at Figure 1. Electrodeposition techniques allow for the widest range of coating thickness, from 5$10 \mathrm{~nm}$ to over $1 \mathrm{~mm}$. Both thermal and sputter PVD allow for the deposition of dense nanoscale coatings. Also, electrodeposition, PVD, and aerosol deposition are each capable of producing submicron thickness coatings.

Typical pore sizes for each deposition process are summarized in Figure 2. To optimize osseointegration, a complex microstructure with porosity of submicron size should be selected. Electrodeposition and aerosol deposition present these submicron pores. Coatings exhibiting little to no porosity, such as plasma spray, PVD, and CVD produce dense coatings with only intergrain voids, inhibiting the penetration of osteogenic cells.

Figure 3 compares the relative cost of each deposition process. The cost for each process is comprised of a few factors, initial investment, processing costs, and consumable cost. Techniques such as PVD, CVD, and aerosol deposition require high initial cost as each utilizes a vacuum chamber. Additionally, CVD requires the use and handling of volatile gases increasing the processing cost. Plasma spray, electrodeposition, and aerosol deposition involve the use of nanoparticles thereby increasing consumable cost. Generally, electrodeposition, plasma spray, and aerosol deposition are the most cost efficient processes for deposition of nanostructured and microstructured coatings.

Finally, a summary of critical assessment of thermal spray, electrodeposition, PVD, CVD, and aerosol deposition as each relates to osseointegration is shown in Table 2. This does not represent an exhaustive list of advantages and disadvantages of each process but offers a brief overview in light of the characteristics discussed in this review. Consideration of 


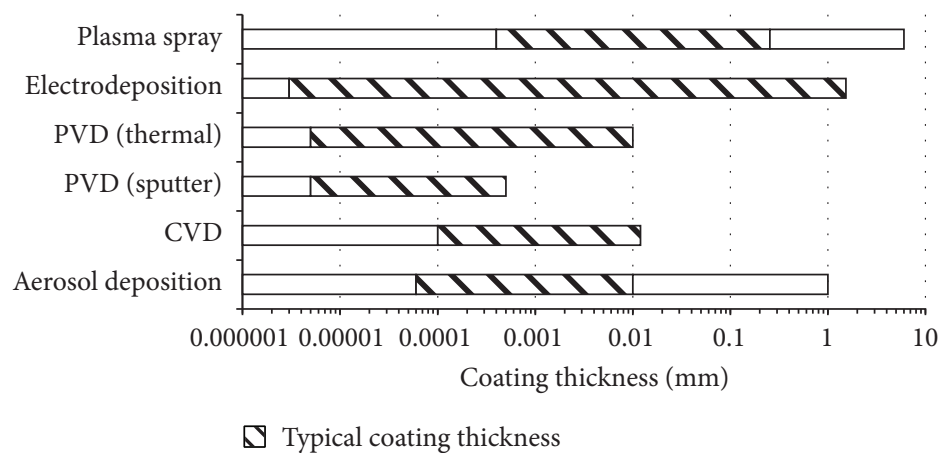

FIGURE 1: Graphical summary of coating thickness of presented processes.

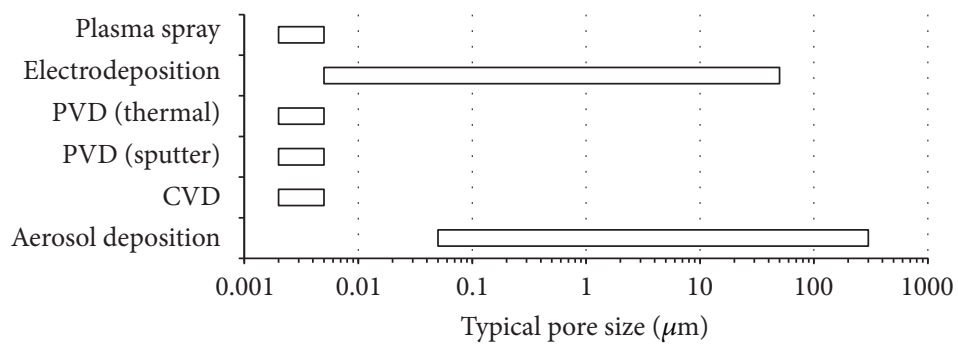

FIGURE 2: Summary of typical pore size for presented processes.

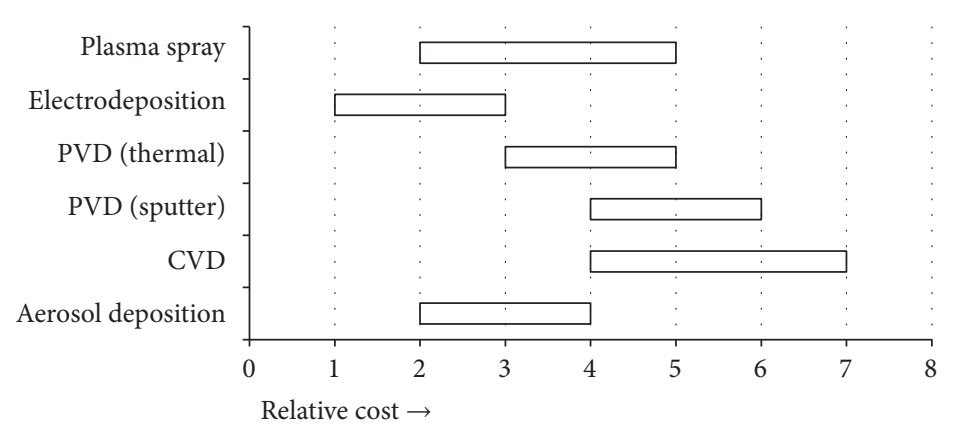

FIGURE 3: Graphical summary of relative cost for presented processes.

other properties and characteristics is necessary in selection of a deposition method for applications unrelated to the osseointegration of bone implants.

\section{Future Research Opportunities}

As plasma spray is the leading deposition method for the application of calcium phosphates, further optimization of parameters is essential for increased adherence and crystallinity and a reduction of amorphous material and residual stress. Improvement of the control of the nanostructure and microstructure of plasma-sprayed coatings and as such, the biocompatible properties, is suggested. Further research in aerosol deposition should focus on increasing deposition efficiency. One suggestion would be the use of a recirculation system to reduce material waste and cost. It is also worthy to mention a recent manufacturing technology, additive manufacturing (AM), here which has a great potential to manufacture metallic implants with proper osseointegration.
$\mathrm{AM}$, both laser and electron beam techniques, is a promising technique used to manufacture highly microstructured components directly from computer-aided design (CAD) data. However, there is little research on the use of AM to deposit discrete coatings on metallic bone implants. This offers another potential area of research to develop computercontrolled microstructured coatings.

\section{Conclusion}

The critical review of microstructured and nanostructured deposition process with regard to osseointegration has led to the following conclusions:

In order for a coating to exhibit bone-bonding properties, it should have microtopography with submicron or nanometer undercuts and have the ability to control and vary pore size from several hundred nanometers to several hundred micrometers. All coating processes reviewed were limited by tradeoffs in biocompatibility, physical and mechanical 
TABLE 2: A critical assessment of microstructured and nanostructured deposition techniques reviewed in this paper.

\begin{tabular}{lll}
\hline Process & Advantages & Disadvantages \\
\hline Plasma spray & (i) High deposition rate & (i) High concentration of amorphous coating and residual stress \\
& $\begin{array}{l}\text { (ii) Low cost } \\
\text { (iii) Wide range of coating materials } \\
\text { (i) High deposition rate }\end{array}$ & (iii) Difficulty coating complex components \\
Electrodeposition & $\begin{array}{l}\text { (ii) Ability to coat complex substrates } \\
\text { (iii) Controlled nanoporous coatings }\end{array}$ & Caustic waste \\
PVD (thermal) & Dense coatings of nanoscale thickness & $\begin{array}{l}\text { (i) Difficulty coating complex components } \\
\text { (ii) Difficulty producing nanoporous coatings }\end{array}$ \\
PVD (sputter) & Ability to coat complex components & $\begin{array}{l}\text { (i) High cost } \\
\text { (ii) Low deposition rate } \\
\text { (i) High temperature process } \\
\text { CVD }\end{array}$ \\
Ability to coat complex components & (iii) Limited coating composition \\
Aerosol deposition & (i) Low cost & Very low deposition efficiency \\
\end{tabular}

properties, making the optimal selection of coating process a challenge. Plasma spray offers a low-cost expeditious deposition method while not facilitating the production of nanostructured and microstructured coatings. Electrodeposition is an excellent solution to produce nanostructured and microstructured coatings, but the use of caustic materials must be taken into account to create viable manufacturing processes. Thermal PVD exhibits capabilities of depositing biocompatible coatings but it faces major challenges for coating complex geometric components. Conversely, sputter PVD offers uniform coating on complex components but at a higher cost. CVD also exhibits uniform coatings but the substrate is subjected to high temperatures and variation in coating materials is difficult as they are a result of chemical reactions within the coating chamber. Additive manufacturing, a promising frontier for biocompatible materials research, could allow the deposition of highly complex computercontrolled microstructure coatings permitting the fabrication of patient-specific implants. Future research needs have been identified to address critical shortcomings in such coating processes, and, when addressed, they will provide solutions that currently limit bone implants.

\section{Competing Interests}

The authors declare that they have no competing interests.

\section{Acknowledgments}

The authors would like to thank Dr. Steven F. Wayne (Department of Mechanical Engineering, The University of Memphis, Memphis, TN, USA) for the helpful discussions, suggestions, and revisions of this work.

\section{References}

[1] P. Kuzyk and E. Schemitsch, "The basic science of peri-implant bone healing," Indian Journal of Orthopaedics, vol. 45, no. 2, pp. 108-115, 2011.
[2] A. F. Mavrogenis, R. Dimitriou, J. Parvizi, and G. C. Babis, "Biology of implant osseointegration," Journal of Musculoskeletal Neuronal Interactions, vol. 9, no. 2, pp. 61-71, 2009.

[3] T. Albrektsson, P.-I. Brånemark, H.-A. Hansson, and J. Lindström, "Osseointegrated titanium implants: requirements for ensuring a long-lasting, direct bone-to-implant anchorage in man," Acta Orthopaedica Scandinavica, vol. 52, no. 2, pp. 155170, 1981.

[4] F. Marco, F. Milena, G. Gianluca, and O. Vittoria, "Peri-implant osteogenesis in health and osteoporosis," Micron, vol. 36, no. 78, pp. 630-644, 2005.

[5] A. Abdulkarim, P. Ellanti, N. Motterlini, T. Fahey, and J. M. O’Byrne, "Cemented versus uncemented fixation in total hip replacement: a systematic review and meta-analysis of randomized controlled trials," Orthopedic Reviews, vol. 5, no. 1, 2013.

[6] P.-I. Branemark, "Osseointegration and its experimental background," The Journal of Prosthetic Dentistry, vol. 50, no. 3, pp. 399-410, 1983.

[7] R. Krishna Alla, K. Ginjupalli, N. Upadhya, M. Shammas, R. Krishna Ravi, and R. Sekhar, "Surface roughness of implants: a review," Trends in Biomaterials and Artificial Organs, vol. 25, no. 3, pp. 112-118, 2011.

[8] D. A. Puleo and A. Nanci, "Understanding and controlling the bone-implant interface," Biomaterials, vol. 20, no. 23-24, pp. 2311-2321, 1999.

[9] G. S. Leventhal, “Titanium, a metal for surgery," The Journal of bone and joint surgery. American volume, vol. 33, no. 2, pp. 473474, 1951.

[10] R. Bothe, L. Beaton, and H. Davenport, "Reaction of bone to multiple metallic implants," Surgery, Gynecology \& Obstetrics, vol. 71, no. 6, pp. 598-602, 1940.

[11] J. E. Davies, "Bone bonding at natural and biomaterial surfaces," Biomaterials, vol. 28, no. 34, pp. 5058-5067, 2007.

[12] V. Karageorgiou and D. Kaplan, "Porosity of 3D biomaterial scaffolds and osteogenesis," Biomaterials, vol. 26, no. 27, pp. 5474-5491, 2005.

[13] C. Sittig, M. Textor, N. Spencer, M. Wieland, and P. Vallotton, "Surface characterization of implant materials c.p. Ti, Ti-6Al$4 \mathrm{~V}$ with different pre-treatments," Journal of Materials Science: Materials in Medicine, vol. 10, no. 1, pp. 35-46, 1999. 
[14] N. Taniguchi, S. Fujibayashi, M. Takemoto et al., "Effect of pore size on bone ingrowth into porous titanium implants fabricated by additive manufacturing: an in vivo experiment," Materials Science and Engineering C, vol. 59, pp. 690-701, 2016.

[15] A. Wennerberg and T. Albrektsson, "Effects of titanium surface topography on bone integration: a systematic review," Clinical Oral Implants Research, vol. 20, no. 4, pp. 172-184, 2009.

[16] H. Zhou, R. Chernecky, and J. E. Davies, "Scanning electron microscopy of the osteoclast-bone interface in vivo," Cells and Materials, vol. 3, no. 2, pp. 141-150, 1993.

[17] P. K. Chu, J. Y. Chen, L. P. Wang, and N. Huang, "Plasmasurface modification of biomaterials," Materials Science and Engineering: R: Reports, vol. 36, no. 5-6, pp. 143-206, 2002.

[18] P. Fauchais and A. Vardelle, "Solution and suspension plasma spraying of nanostructure coatings," in Advanced Plasma Spray Applications, pp. 149-188, InTech, 2012.

[19] M. C. Kuo and S. K. Yen, "The process of electrochemical deposited hydroxyapatite coatings on biomedical titanium at room temperature," Materials Science and Engineering: $C$, vol. 20, no. 1-2, pp. 153-160, 2002.

[20] T. Ling, J. Lin, J. Tu et al., "Mineralized collagen coatings formed by electrochemical deposition," Journal of Materials Science: Materials in Medicine, vol. 24, no. 12, pp. 2709-2718, 2013.

[21] I. Gurrappa and L. Binder, "Electrodeposition of nanostructured coatings and their characterization-a review," Science and Technology of Advanced Materials, vol. 9, no. 4, Article ID 043001, 2008.

[22] F. Z. Cui and Z. S. Luo, "Biomaterials modification by ion-beam processing," Surface and Coatings Technology, vol. 112, no. 1-3, pp. 278-285, 1999.

[23] P. Sioshansi and E. J. Tobin, "Surface treatment of biomaterials by ion beam processes," Surface and Coatings Technology, vol. 83, no. 1-3, pp. 175-182, 1996.

[24] G. Dearnaley and J. H. Arps, "Biomedical applications of diamond-like carbon (DLC) coatings: a review," Surface and Coatings Technology, vol. 200, no. 7, pp. 2518-2524, 2005.

[25] R. Bosco, E. R. U. Edreira, J. G. C. Wolke, S. C. G. Leeuwenburgh, J. J. J. P. van den Beucken, and J. A. Jansen, "Instructive coatings for biological guidance of bone implants," Surface and Coatings Technology, vol. 233, pp. 91-98, 2013.

[26] K. Balani, R. Anderson, T. Laha et al., "Plasma-sprayed carbon nanotube reinforced hydroxyapatite coatings and their interaction with human osteoblasts in vitro," Biomaterials, vol. 28, no. 4, pp. 618-624, 2007.

[27] Y. Yang, K.-H. Kim, and J. L. Ong, "A review on calcium phosphate coatings produced using a sputtering process-an alternative to plasma spraying," Biomaterials, vol. 26, no. 3, pp. 327-337, 2005.

[28] P. Cheang and K. A. Khor, "Addressing processing problems associated with plasma spraying of hydroxyapatite coatings," Biomaterials, vol. 17, no. 5, pp. 537-544, 1996.

[29] A. Mahapatro, "Bio-functional nano-coatings on metallic biomaterials," Materials Science and Engineering C, vol. 55, pp. 227251, 2015.

[30] M. F. Morks, N. F. Fahim, and A. Kobayashi, "Structure, mechanical performance and electrochemical characterization of plasma sprayed $\mathrm{SiO} 2 / \mathrm{Ti}$-reinforced hydroxyapatite biomedical coatings," Applied Surface Science, vol. 255, no. 5, pp. 34263433, 2008.

[31] W.-K. Lee, S.-M. Lee, and H.-M. Kim, "Effect of surface morphology of calcium phosphate on osteoblast-like HOS cell responses," Journal of Industrial and Engineering Chemistry, vol. 15, no. 5, pp. 677-682, 2009.

[32] D. M. Dziedzic, I. H. Savva, D. S. Wilkinson, and J. E. Davies, "Osteoconduction on, and bonding to, calcium phosphate ceramic implants," in Proceedings of the Material Research Society Symposium Proceeding, pp. 147-156, 1996.

[33] N. Sato, K. Kubo, M. Yamada et al., "Osteoblast mechanoresponses on Ti with different surface topographies," Journal of Dental Research, vol. 88, no. 9, pp. 812-816, 2009.

[34] I. Wall, N. Donos, K. Carlqvist, F. Jones, and P. Brett, "Modified titanium surfaces promote accelerated osteogenic differentiation of mesenchymal stromal cells in vitro," Bone, vol. 45, no. 1, pp. 17-26, 2009.

[35] K. Takatsuka, T. Yamamuro, T. Nakamura, and T. Kokubo, "Bone-bonding behavior of titanium alloy evaluated mechanically with detaching failure load," Journal of Biomedical Materials Research, vol. 29, no. 2, pp. 157-163, 1995.

[36] D. Khang, J. Lu, C. Yao, K. M. Haberstroh, and T. J. Webster, "The role of nanometer and sub-micron surface features on vascular and bone cell adhesion on titanium," Biomaterials, vol. 29, no. 8, pp. 970-983, 2008.

[37] M. Sulzer, "An introduction to thermal spray," Company Brochure, no. 5, pp. 1-24, 2012.

[38] H. Herman and R. A. Sulit, "Thermal spray coatings", in ASM Handbook, vol. 6 of Welding, Brazing, Soldering, pp. 1004-1009, 1993.

[39] P. L. Fauchais, J. V. R. Heberlein, and M. I. Boulos, Thermal Spray Fundamentals, Springer, 2014.

[40] H. Fukanuma and N. Ohno, "A study of adhesive strength of cold spray coatings," in Proceedings of the International Thermal Spray Conference, pp. 329-334, Osaka, Japan, May 2004.

[41] H. Guosheng and W. Hongren, "De-Laval-Type nozzle for cold spraying," CN 10116849 B, May 2010.

[42] M. R. Hasniyati, H. Zuhailawati, and S. Ramakrishnan, "A statistical prediction of multiple responses using overlaid contour plot on hydroxyapatite coated magnesium via cold spray deposition," Procedia Chem, vol. 19, pp. 181-188, 2016.

[43] D. R. Marantz, "High-velocity flame spray apparatus and method of forming materials," US 5019686 A, May 1991.

[44] T. C. Hanson, C. M. Hackett, and G. S. Settles, "Independent control of HVOF particle velocity and temperature," Journal of Thermal Spray Technology, vol. 11, no. 1, pp. 75-85, 2002.

[45] K. A. Khor, H. Li, and P. Cheang, "Characterization of the bone-like apatite precipitated on high velocity oxy-fuel (HVOF) sprayed calcium phosphate deposits," Biomaterials, vol. 24, no. 5, pp. 769-775, 2003.

[46] R. M. Poorman, H. B. Sargent, and L. Headlee, "Method and apparatus utilizing detonation waves for spraying and other purposes," US Patent No. 2714563, 1955.

[47] M. Geetha, S. Sathish, K. Chava, and S. V. Joshi, "Detonation gun sprayed $\mathrm{Al}_{2} \mathrm{O}_{3}-13 \mathrm{TiO}_{2}$ coatings for biomedical applications," Surface Engineering, vol. 30, no. 4, pp. 229-236, 2014.

[48] R. Z. Legeros and R. G. Craig, "Strategies to affect bone remodeling: osteointegration," Journal of Bone and Mineral Research, vol. 8, supplement 2, pp. S583-S596, 1993.

[49] D. M. Yenni, W. C. Mcgill, and J. W. Lyle, "Electric arc spraying," US 2982845 A, May 1961.

[50] D. R. Marantz and K. A. Kowalsky, "High velocity electric-arc spray apparatus and method of forming materials," US Patente 5442153, 1994. 
[51] D. R. Marantz, K. A. Kowalsky, J. R. Baughman, and D. J. Cook, "Plasma transferred wire arc thermal spray apparatus and method," US A, Article ID 5808270, p. 15, 1998.

[52] R. Wasserman, J. Quaas, J.-C. Chalard, L. Noel, and H.-T. Steine, "Installation for surfacing using plasma-arc welding," US Patent 4125754, 1987.

[53] J. Ružić, M. Vilotijević, D. Božić, and K. Raić, “Understanding plasma spraying process and characteristics of DC-arc plasma gun (PJ-100)," Metallurgical \& Materials Engineering, vol. 18, no. 4, pp. 273-282, 2012.

[54] R. d'Haese, L. Pawlowski, M. Bigan, R. Jaworski, and M. Martel, "Phase evolution of hydroxapatite coatings suspension plasma sprayed using variable parameters in simulated body fluid," Surface and Coatings Technology, vol. 204, no. 8, pp. 1236-1246, 2010.

[55] Y. C. Yang, E. Chang, B. H. Hwang, and S. Y. Lee, "Biaxial residual stress states of plasma-sprayed hydroxyapatite coatings on titanium alloy substrate," Biomaterials, vol. 21, no. 13, pp. 1327-1337, 2000.

[56] Y.-L. Chang, D. Lew, J. B. Park, and J. C. Keller, "Biomechanical and morphometric analysis of hydroxyapatite-coated implants with varying crystallinity," Journal of Oral and Maxillofacial Surgery, vol. 57, no. 9, pp. 1096-1108, 1999.

[57] Y. Otsuka, H. Kawaguchi, and Y. Mutoh, "Cyclic delamination behavior of plasma-sprayed hydroxyapatite coating on Ti-6Al$4 \mathrm{~V}$ substrates in simulated body fluid," Materials Science and Engineering C, vol. 67, pp. 533-541, 2016.

[58] R. Hull and C. Ruebensaal, “Electroplating,” US Patent 2312097, 1943.

[59] K. Grandfield and I. Zhitomirsky, "Electrophoretic deposition of composite hydroxyapatite-silica-chitosan coatings," Materials Characterization, vol. 59, no. 1, pp. 61-67, 2008.

[60] Y.-J. Oh, S.-H. Chung, and M.-S. Lee, "Optimization of thickness uniformity in electrodeposition onto a patterned substrate," Materials Transactions, vol. 45, no. 10, pp. 3005-3010, 2004.

[61] A. Yumoto, N. Niwa, F. Hiroki, and T. Yamamoto, "Physical vapor deposition apparatus and physical vapor deposition method," US 20110189390 Al, August 2011.

[62] K. D. Kennedy, "Method of physical vapor deposition," US Patent 3912826, 1975.

[63] A. Mubarak, E. Hamzah, and M. R. M. Toff, "Review of physical vapour deposition (PVD) techniques for hard coating," J-Mek, vol. 20, no. 20, pp. 42-51, 2005.

[64] A. A. Snaper, “Arc deposition process and apparatus," US Patent 3625848, 1971.

[65] D. M. Sanders and A. Anders, "Review of cathodic arc deposition technology at the start of the new millennium," Surface and Coatings Technology, vol. 133-134, pp. 78-90, 2000.

[66] S. Onder, F. N. Kok, K. Kazmanli, and M. Urgen, "Magnesium substituted hydroxyapatite formation on ( $\mathrm{Ti}, \mathrm{Mg}) \mathrm{N}$ coatings produced by cathodic arc PVD technique," Materials Science and Engineering: C, vol. 33, no. 7, pp. 4337-4342, 2013.

[67] H. N. Takeshi Nakamura and S. Kato, "Magnetron sputtering apparatus," US 4309266 A, January 1982.

[68] A. Mubarak, E. Hamzah, and M. R. M. Toff, "Review of physical vapour deposition (PVD) techniques for hard coating," Jurnal Mekanikal, vol. 20, no. 20, pp. 42-51, 2005.

[69] F. Z. Cui, Z. S. Luo, and Q. L. Feng, "Highly adhesive hydroxyapatite coatings on titanium alloy formed by ion beam assisted deposition," Journal of Materials Science: Materials in Medicine, vol. 8, no. 7, pp. 403-405, 1997.
[70] I. Nakayama, A. Suzuki, Y. Kusumoto, K. Takakuwa, and T. Ikuta, "Method of forming a thin film by chemical vapor deposition," US 4800105 A, January 1989.

[71] G. Giavaresi, L. Ambrosio, G. A. Battiston et al., "Histomorphometric, ultrastructural and microhardness evaluation of the osseointegration of a nanostructured titanium oxide coating by metal-organic chemical vapour deposition: an in vivo study," Biomaterials, vol. 25, no. 25, pp. 5583-5591, 2004.

[72] H.-C. Choe, "Photofunctionalization of EB-PVD HA-coated nano-pore surface of Ti-30Nb-xZr alloy for dental implants," Surface and Coatings Technology, vol. 228, no. 1, pp. S470-S476, 2013.

[73] Y.-H. Jeong, B.-H. Moon, H.-C. Choe, and W. A. Brantley, "Surface characteristics of hydroxyapatite-coated layer prepared on nanotubular Ti-35Ta-xHf alloys by EB-PVD," Thin Solid Films, vol. 549, pp. 147-153, 2013.

[74] Y. Liu, Y.-Y. Wang, G.-J. Yang, J.-J. Feng, and K. Kusumoto, "Effect of nano-sized TiN additions on the electrical properties of vacuum cold sprayed SiC coatings," Journal of Thermal Spray Technology, vol. 19, no. 6, pp. 1238-1243, 2010.

[75] F. Cao, H. Park, G. Bae, J. Heo, and C. Lee, "Microstructure evolution of titanium nitride film during vacuum kinetic spraying," Journal of the American Ceramic Society, vol. 96, no. 1, pp. 40-43, 2013.

[76] D. Hanft, J. Exner, M. Schubert, T. Stöcker, P. Fuierer, and R. Moos, "An overview of the Aerosol Deposition method: process fundamentals and new trends in materials applications," Journal of Ceramic Science and Technology, vol. 6, no. 3, pp. 147-181, 2015.

[77] C. Boissiere, D. Grosso, A. Chaumonnot, L. Nicole, and C. Sanchez, "Aerosol route to functional nanostructured inorganic and hybrid porous materials," Advanced Materials, vol. 23, no. 5, pp. 599-623, 2011.

[78] B.-D. Hahn, D.-S. Park, J.-J. Choi et al., "Effect of the HA/ $\beta$ TCP ratio on the biological performance of calcium phosphate ceramic coatings fabricated by a room-temperature powder spray in vacuum," Journal of the American Ceramic Society, vol. 92, no. 4, pp. 793-799, 2009.

[79] B.-D. Hahn, Y.-L. Cho, D.-S. Park et al., "Effect of fluorine addition on the biological performance of hydroxyapatite coatings on Ti by aerosol deposition," Journal of Biomaterials Applications, vol. 27, no. 5, pp. 587-594, 2013.

[80] M. Kubo, Y. Ishihara, Y. Mantani, and M. Shimada, "Evaluation of the factors that influence the fabrication of porous thin films by deposition of aerosol nanoparticles," Chemical Engineering Journal, vol. 232, pp. 221-227, 2013. 

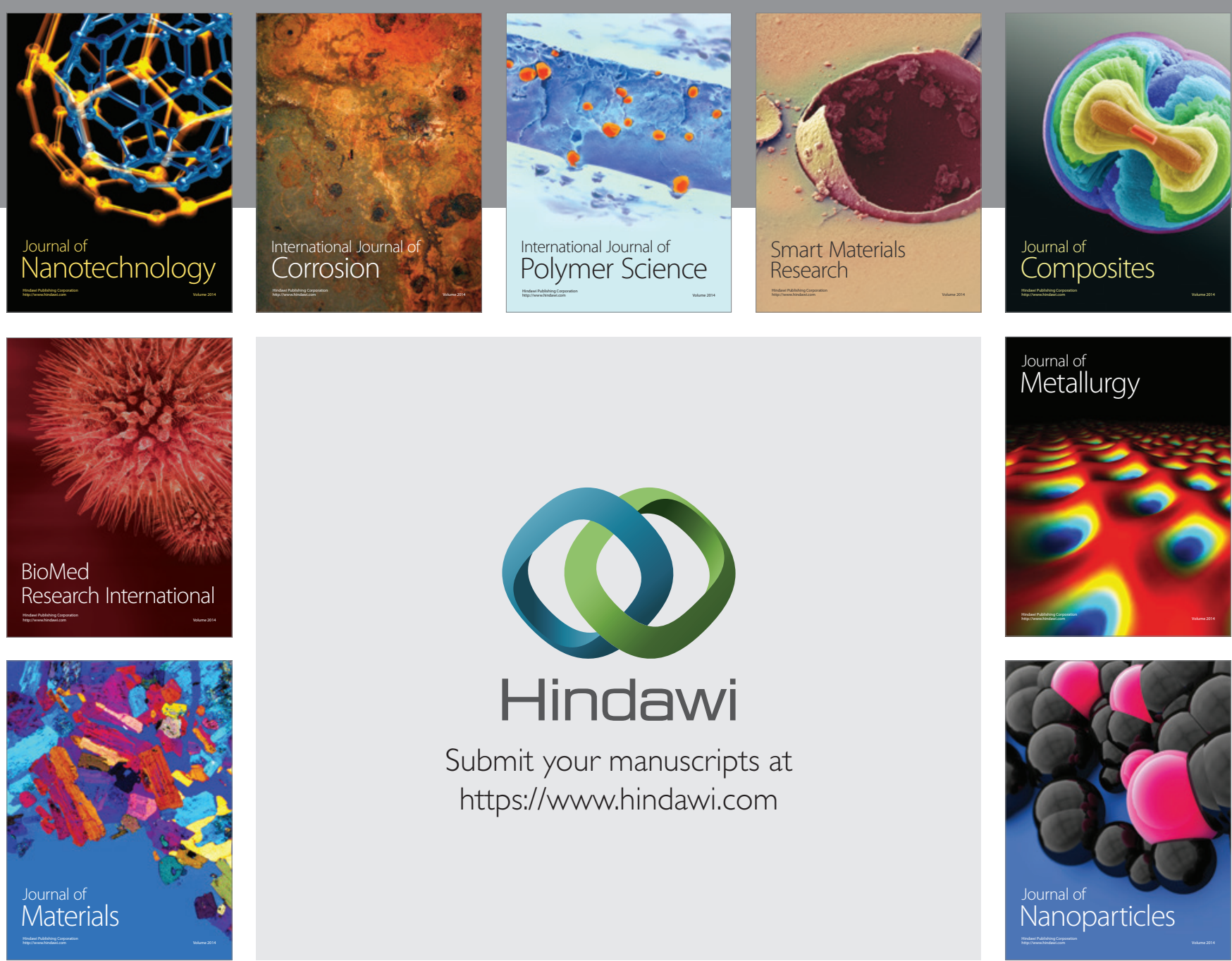

\section{Hindawi}

Submit your manuscripts at

https://www.hindawi.com

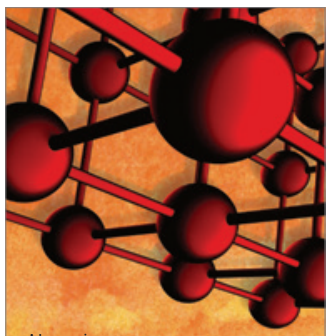

Materials Science and Engineering
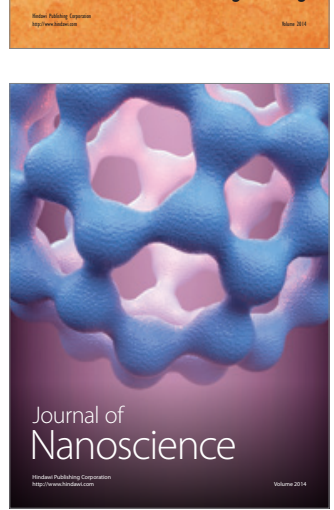
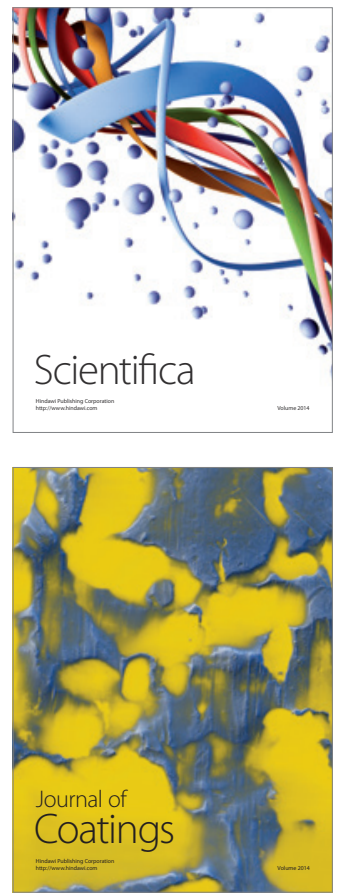
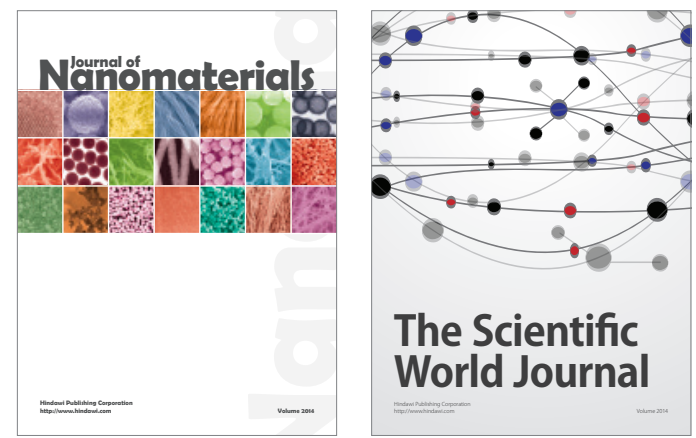

The Scientific World Journal
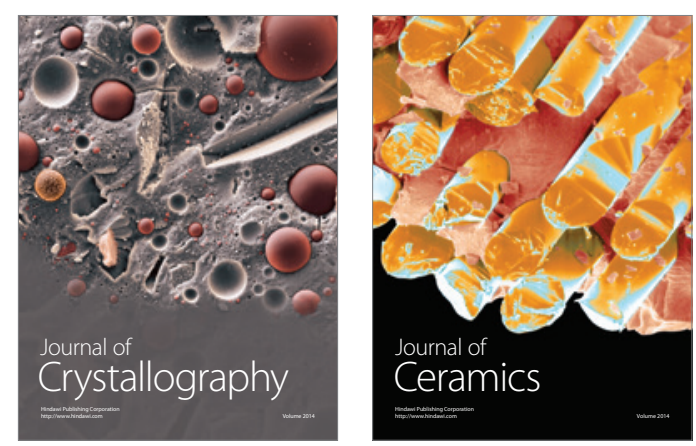
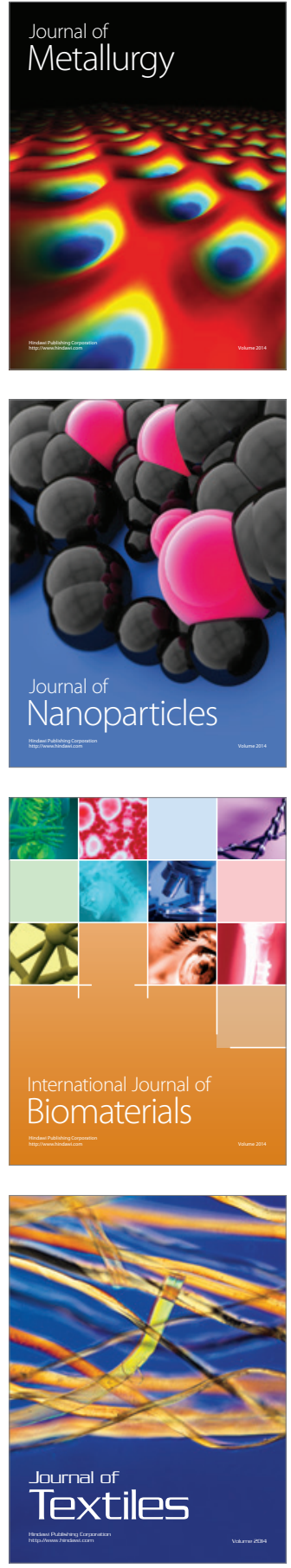